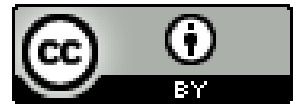

\title{
QUESTÕES ACERCA DO GENOCÍDIO NEGRO NO BRASIL ${ }^{1}$
}

Resumo: O racismo é estrutural e estruturante do capitalismo. Buscamos neste trabalho compreender as dimensões espaciais do racismo na cidade. Nossa metodologia envolve tanto escrevivências, isto é, uma escrita a partir da experiência vivida e percebida através de nossa corporeidade negra quanto análises bibliográficas acerca do racismo e do antirracismo brasileiro. Nossa hipótese é que o negro foi inventado como um problema espacial pela branquitude desde o inicio de nossa formação. Esse projeto racial em curso tem promovido mortes 'justificadas' dos negros, isto é, necropolíticas. Nosso objetivo é analisar como esse problema espacial foi inventado, quais os dispositivos espaciais que engendrou e como se tornou inerente à produção social do espaço urbano brasileiro.

Palavras-Chave: Negro - Necropolítica - Genocídio - Problema Espacial

\section{QUESTIONS ABOUT THE BLACK GENOCIDE IN BRAZIL}

Abstract: Racism is structural and structuring of capitalism. We seek in this work to understand the spatial dimensions of racism in the city. Our methodology involves both registries, that is, a writing based on the experience lived and perceived through our black corporeality, as well as bibliographic analyzes about Brazilian racism and anti-racism. Our hypothesis is that black people were invented as a spatial problem due to whiteness since the beginning of our formation. This ongoing racial project has promoted 'justified' deaths of blacks, that is, necropolitical ones. Our objective is to analyze how this spatial problem was invented, which spatial devices it created and how it became inherent to the social production of the Brazilian urban space.

Key-words: Negro - Necropolitics - Genocide - Spatial Problem

\section{PREGUNTAS SOBRE EL GENOCIDIO NEGRO EN BRASIL}

Resumen: El racismo es estructural y estructurante del capitalismo. En este trabajo buscamos comprender las dimensiones espaciales del racismo en la ciudad. Nuestra

\footnotetext{
${ }^{1}$ Esta investigação faz parte da pesquisa sobre espaço urbano e relações raciais do NEGRA - Núcleo de Estudo e Pesquisa em Geografia Regional da África e da Diáspora. Parte das ideias aqui abordadas foram apresentadas no COPENE SUDESTE 2019 na cidade de Vitória - Espírito Santo. Neste trabalho, buscamos ampliar e aprofundar alguns pontos explorados no trabalho anterior.

2 Professor do Departamento e do Programa de Pós-Graduação em Geografia FFP-UERJ e Professor do Programa de Pós-Graduação em Cultura e Territorialidades - UFF. Coordenador do NEGRA (Núcleo de Estudo e Pesquisa em Geografia Regional da África e da Diáspora) Email: araujo.denilson@gmail.com
} 
metodología involucra tanto registros, es decir, una escritura basada en la experiencia vivida y percibida a través de nuestra corporeidad negra, como también análisis bibliográficos sobre el racismo y el antirracismo brasileño. Nuestra hipótesis es que las personas negras fueron inventadas como un problema espacial debido a la blancura desde el comienzo de nuestra formación. Este proyecto racial en curso ha promovido muertes 'justificadas' de negros, es decir, necropolíticos. Nuestro objetivo es analizar cómo se inventó este problema espacial, qué dispositivos espaciales creó y cómo se hizo inherente a la producción social del espacio urbano brasileño.

Palabras clave: Negro - Necropolítica - Genocidio - Problema espacial

\section{QUESTIONS SUR LE GÉNOCIDE DES NOIRS AU BRÉSIL}

Résumé: Le racisme est structurel et structurant du capitalisme. Nous cherchons dans ce travail à comprendre les dimensions spatiales du racisme dans la ville. Notre méthodologie implique à la fois des registres, c'est-à-dire une écriture basée sur l'expérience vécue et perçue à travers notre corporéité noire, ainsi que des analyses bibliographiques sur le racisme et l'antiracisme brésiliens. Notre hypothèse est que les Noirs ont été inventés comme un problème spatial dû à la blancheur depuis le début de notre formation. Ce projet racial en cours a favorisé les décès «justifiés» de Noirs, c'està-dire les décès nécropolitiques. Notre objectif est d'analyser comment ce problème spatial a été inventé, quels dispositifs spatiaux il a créés et comment il est devenu inhérent à la production sociale de l'espace urbain brésilien.

Mots clés: Noir - Nécropolitiques - Génocide - Problème spatial.

\section{INTRODUÇÃO}

No Brasil e no mundo os temas da raça e do racismo se constituíram como uma das principais engrenagens do capitalismo. Desde o início da formação do capitalismo a hierarquia do humano tem a raça como um dos definidores de quem vive e morre. $\mathrm{Na}$ escala brasileira esse debate envolve uma enorme complexibilidade. Somos um país de formação colonial que teve a escravidão como uma instituição definidora de outras instituições. Logo, foi se constituindo um sistema complexo e ambivalente de dominação/opressão/exploração/resistência/r-existência que intersecciona múltiplas hierarquias que se renovam a cada momento e contexto espacial. O fim do colonialismo não significou o fim da colonialidade (QUIJANO, 2005), desta forma, instituições não foram decolonizadas ${ }^{3}$. Daí a grande dificuldade dos órgãos do Estado de enfrentar a

\footnotetext{
${ }^{3}$ Entendemos a necessidade de pensar e construirmos outros processos de descolonizações mais amplo, plurais e radicais. Processos de descolonização que não rompa apenas com o colonialismo, mas também,
} 
questão racial brasileira. A ação do Movimento $\mathrm{Negro}^{4}$ cada vez mais pressiona pela responsabilização das ações do Estado, a decolonização das instituições brasileiras e a criação de políticas públicas que combatam espacialmente o racismo. O Estado brasileiro, ao contrário do que se espera de um país que deseja ser democrático, tem sido acusado como um dos principais indutores do chamado genocídio negro.

O racismo é estrutural e estruturante da sociedade brasileira (ALMEIDA, 2018) que busca diminuir potencias de existir de não-brancos. O racismo brasileiro expressa um padrão de poder que institui privilégios a partir da hierarquia do humano por raça, a colonialidade do poder, lembra Quijano (2005). O racismo em nossa sociedade estruturou um padrão de normalidade que naturaliza relações racialmente desiguais instituídas na produção social do espaço. No entanto, a leitura espacial do racismo tem sido negligenciada. O campo da Geografia e das disciplinas espaciais podem fornecer interessantes caminhos para compreender a questão racial brasileira. Felizmente cresce, mesmo que não em termos expressivos, o número de estudos e pesquisas que buscam compreender as dimensões espaciais do racismo e do antirracismo. Este processo envolve uma decolonização do saber e a compreensão das formas de lutas negras ao longo da história e da geo-grafia dos lugares (GONÇALVES, 2001).

Neste artigo buscamos construir uma genealogia do que tem sido chamado de genocídio negro. Nossa metodologia envolve tanto escrevivências (EVARISTO, 2013), isto é, uma escrita a partir da nossa experiência vivida e percebida desta terrível violência através da nossa corporeidade negra quanto análises bibliográficas acerca do racismo e

com a colonialidade. Isso significa uma estilhaçamento e ruptura com o círculo infernal que inventou e capturou o negro numa prisão que não há escapatória e num falso humanismo que só vê emancipação e lutas dos homens, brancos, heterossexuais e cristãos.

Seguimos a sugestão de Oliveira (2018, p. 101-102) quando afirma que: "Decolonizar, significaria então, no campo da educação, uma práxis baseada numa insurgência educativa propositiva - portanto não somente denunciativa - por isso o termo 'DE' e não 'DES' - em que o termo insurgir representa a criação e a construção de novas condições sociais, políticas e culturais e de pensamento. Em outras palavras, a construção de uma noção e visão pedagógica que se projeta muito além dos processos de ensino e de transmissão de saber, uma pedagogia concebida como política cultural, envolvendo não apenas os espaços educativos formais, mas também as organizações dos movimentos sociais. DEcolonizar na educação é construir outras pedagogias além da hegemônica. DEScolonizar é apenas denunciar as amarras coloniais e não constituir outras formas de pensar e produzir conhecimento".

${ }^{4}$ Mbembe (2014) diferencia a palavra negro em maiúsculo e minúsculo para afirmar uma lógica emancipadora e protagonista (Negro) frente uma lógica de submissão e humilhação (negro). Aqui negro em minúsculo será o projeto de espaço hegemônico e Negro, em maiúsculo, o projeto de contra-espaço. 
do antirracismo brasileiro. Nossa hipótese é que o negro foi inventado como um problema espacial pela branquitude desde o inicio de nossa formação. Esse é o projeto racial (MOREIRA, 2019) em curso que tem promovido mortes 'justificadas' dos negros, ou seja, um regime de calculada brutalidade e terrorismo (JAMES, 2010) definindo uma necropolítica (MBEMBE, 2006). Nosso objetivo é analisar como esse problema espacial foi inventado, quais os dispositivos espaciais que engendrou e como se tornou inerente à produção social do espaço urbano brasileiro.

\section{NEGRO: UM PROBLEMA ESPACIAL DA BRANQUITUDE}

Vivemos numa sociedade racialmente desigual. Falar sobre racismo significa compreender uma das dimensões da nossa sociedade que é geralmente silenciada. $\mathrm{O}$ racismo brasileiro é um sistema complexo que intersecciona múltiplas hierarquias. Ele é dinâmico, plural e se inscreve na produção social do espaço. Da localização e distribuição das pessoas, bens e serviços ao sistema de valores que regem uma determinada organização espacial, a raça tem sido utilizada como dispositivo de poder. O racismo é um reflexo social, um condicionante e dispositivo de interrupção da ação. Ele se inscreve no sistema político, econômico, cultural-religioso, epistêmico, etc. O racismo produzir uma drenagem das energias negras em favor dos privilégios espaciais da branquitude.

Almeida (2018) afirma que o racismo brasileiro está inscrito nas engrenagens da vida social, isto é, o modo 'normal' como funciona as relações familiares, políticas, jurídicas, econômicas, entre outras relações sociais. Não é uma patologia e nem um desarranjo institucional. Os comportamentos individuais, coletivos e os processos institucionais derivam de uma sociedade estruturada pelo racismo. $\mathrm{O}$ "racismo é regra e não exceção" (Idem, 2018, p. 38). Logo, o racismo não pode ser compreendido apenas como coisa do passado, mas como uma vontade de poder no presente. Em nossa sociedade o racismo foi definido como um padrão de normalidade (ALMEIDA, 2018) para justificar uma sociedade escravocrata. Esse padrão de normalidade, mesmo após o fim da escravidão, não foi eliminado. Instituiu-se um falso complexo de inferioridade e dependência sobre os negros e um falso complexo de superioridade dos brancos como algo natural e não como algo historicamente constituído (FANON, 2008). Esses complexos buscam instituir no negro uma automutilação e uma auto-ilusão de que falar, 
pensar e agir como branco seria o símbolo da razão, do correto e do belo. Nesta visão, o negro é um problema. A solução é o extermínio físico e/ou torna-se branco (GUERREIRO RAMOS, 1957). Contudo, a invenção deste problema foi imanente a um projeto espacial, pois era preciso impor uma ordem espacial das relações raciais para evitar os questionamentos de privilégios que não foram abolidos (OLIVEIRA, 2011). Santos (1996) lembra que Guerreiro Ramos já nos alertava sobre essa ideia

Para Guerreiro Ramos, negro não é, pois, uma raça (a rigor raça não existe), mas se fosse, a nada de progressista levaria toma-lo como tal. Negro é uma configuração social, um lugar que pode ser ocupado mesmo por não negros (assim como o lugar do branco pode ser ocupado por um preto ou mulato). Como se descreve esse lugar?

As coordenadas para fixar o negro como lugar seriam, o fenótipo (crioulo), a condição social (pobre), o patrimônio cultural (popular), a origem histórica (ascendência africana) e identidade (autodefinição e definição pelo outro). A coordenada mais fraca é o fenótipo, uma vez que a maioria da nossa população tende para o escuro. Brasileiro é, como se deduz, o melhor sinônimo de negro; e branco um sinônimo de não brasileiro.

Estamos diante de uma radicalidade maior do que a de tomar o negro como raça discriminada em luta pelos seus direitos. Essa radicalidade consiste em apresentar o problema negro como o problema do Brasil; e, consequentemente, abrir condições de inserir os seus problemas na agenda nacional (SANTOS, 1996, p. 223).

As coordenadas do negro como lugar que estão apontadas acima (o fenótipo, a condição social, o patrimônio cultural, a origem histórica e a identidade) ${ }^{5}$ são elementos repertoriados pelo racismo para constranger, frustrar, isolar, interditar e/ou impedir o uso e a apropriação de certos espaços. Ou seja, eliminar o mal-estar diante do corpo negro criando atitudes de reserva (FREUD, 2010; SIMMEL, 1967) do branco diante da proximidade espacial do negro. Esquemas de percepção da branquitude transformados em práticas espaciais de segregação são criados. Essas atitudes de reserva dependem do contexto espaço-temporal (Idem). A atitude de reserva "não está relacionada apenas a condição econômica do indivíduo, mas também, se refere aos preconceitos e estereótipos raciais instituídos no imaginário social e nas consciências das pessoas sobre os negros e moradores de morros, favelas e comunidades" (OLIVEIRA, 2019). Rufino (Idem) afirma que o chamado problema negro é verdadeiramente o problema da sociedade brasileira [inventado pela branquitude]. Enfrentar esse problema significa compreender a estrutura

\footnotetext{
${ }^{5}$ Acrescentamos as coordenadas do negro como lugar a indumentária, a forma de andar e falar.
} 
hierárquica da nossa sociedade. Assim, o negro como lugar é uma experiência de viver constantemente no limite. Esses imaginários são marcados por estereótipos como práticas significantes (HALL, 2010)

El estereotipo como práctica significante es central a la representación de la diferencia racial. Pero ¿qué es un estereotipo? ¿Cómo funciona en la realidad? [...] Los estereotipos retienen unas cuantas características "sencillas, vividas, memorables, fácilmente percibidas y ampliamente reconocidas" acerca de una persona, reducen todo acerca de una persona a esos rasgos, los exageran y simplifican y los fijan sin cambio o desarrollo hasta la eternidad. Este es el proceso que describimos anteriormente. Por consiguiente, el primer punto es: la estereotipación reduce, esencializa, naturaliza y fija la "diferencia". Segundo, la estereotipación despliega una estrategia de "hendimiento". Divide lo normal y lo aceptable de lo anormal y de lo inaceptable. Entonces excluye o expulsa todo lo que no encaja, que es diferente. [...]

Así, otro rasgo de la estereotipación es su práctica de "cerradura" y exclusión. Simbólicamente fija límites y excluye todo lo que no pertenece.

La estereotipación es, en otras palabras, parte del mantenimiento del orden social y simbólico. Establece una frontera simbólica entre lo "normal" y lo "desviante", lo "normal" y lo "patológico", lo "aceptable" y lo "inaceptable", lo que "pertenece" y lo que no pertenece o lo que es "Otro", entre "internos" y "externos", nosotros y ellos. Facilita la "unión" o el enlace de todos nosotros que somos "normales" en una "comunidad imaginada" y envía hacia un exilio simbólico a todos ellos - los "Otros"- que son de alguna forma diferentes, "fuera de límites". Mary Douglas (1966), por ejemplo, decía que cualquier cosa que está "fuera de lugar" se considera contaminada, peligrosa, tabú. Sentimientos negativos se congregan a su alrededor. Debe ser simbólicamente excluida si se quiere restablecer la "pureza" de la cultura. La teórica feminista Julia Kristeva (1982) denomina tales grupos expulsados o excluidos como abyectos (del significado en latín, literalmente desechado).

El tercer punto es que la estereotipación tiende a ocurrir donde existen grandes desigualdades de poder. El poder es usualmente dirigido contra el grupo subordinado o excluido. Un aspecto de este poder, de acuerdo con Dyer, es el etnocentrismo: "la aplicación de las normas de la cultura de uno a las de otros" (BROWN 1965: 183); (HALL, 2010, p. 429/430)

Apesar da força desses estereótipos interferindo na vida dos negros e ademais, dados detalhados sobre violência, letalidade e desigualdade social terem a marca do componente racial, uma retórica intransigente (HIRSCHMAN, 1992), especialmente nas redes sociais, tem apontado fatos sociais como vitimismo e mimimi. Busca-se desacreditar a existência do racismo no Brasil. Os defensores destes argumentos, além de difundirem notícias falsas, insistem que se o racismo brasileiro existisse diferente dos EUA e o sulafricano, nunca teria criado um problema espacial, pois ele apresentaria casos muito episódicos. Essas narrativas demonstram um pacto narcísico da branquitude (BENTO, 
2002). Esse pacto narcísico reproduz "um pacto silencioso de apoio e fortalecimento aos iguais. Um pacto que visa preservar, conservar a manutenção de privilégios e de interesses" (BENTO, 2002, p. 105/106).

O racismo estabelece dispositivos despontencializadores de modos de ser, de estar e de existir. Ele não é questão de ato falho, arbitrários e intencionais (MOREIRA, 2019), mas um padrão de poder que cria uma máquina (re)produtora de mentalidades e hierarquias raciais na produção social do espaço. Essas mentalidades além de dissimular a acumulação de privilégios raciais definem o branco como o paradigma, aquele que se tem confiança e o que recebe um salário público psicológico, como afirma William Du Bois (apud SCHUCMAN, 2012), ou seja, o branco pobre possui um capital racial que lhe permite usar os espaços dos brancos ricos sem sofrer qualquer tipo de interdição e/ou constrangimento racial. O negro não possui esse capital, mesmo o negro rico ${ }^{6}$. Logo, precisa sempre de um cartão de visita (OLIVEIRA, 2011). São espaços recortados por grafias de poder racial, heteronormativa, de classe generificada, dos espaços vitrines que reduz as relações materiais e simbólicas de negros, pobres, mulheres, LGBTQI+ (BARBOSA \& BARBOSA, 2017). Define-se aí o complexo de dependência (FANON, 2008). Nesta lógica, a tutela é o destino esperado para os negros para iludir-se com a superação da zona do não-ser ${ }^{7}$. Nesta lógica de negação e si, a definição do seu ser é intermediada por outro. "Para tanto, o não-ser buscará usar máscaras brancas como condição para se elevar à condição de ser" (BERNARDINO-COSTA, 2016, p. 507). Esses falsos complexos além de camuflar a vontade de poder da branquitude, instituem

\footnotetext{
6 "Há um disseminado desconforto, irritação, talvez medo e apreensão quanto aos negros que ascendem. São considerados arrogantes, agressivos, e freqüentemente aparecem expressões que revelam que esses negros invadiram um território que o branco considera seu. Pode-se levantar a hipótese de resistência à mudança da situação das relações raciais, bem como de defesa de espaços de poder e privilégio" (BENTO, 2002, p.156).

7 "Zona do ser e zona do não-ser é uma divisão maniqueísta imposta pelo colonialismo. Embora o olhar imperial queira produzir cada uma dessas zonas como homogêneas, para Fanon nenhuma delas é homogênea. Entre os não-seres, inferiorizados pela cultura imperial, há uma outra divisão: entre subhumanos e não-humanos" (BERNARDINO-COSTA, 2016, p.508).

“A constatação de divisões no interior da zona do não-ser permite uma conexão entre as contribuições de Fanon e as recentes discussões em torno do conceito de interseccionalidade. Em outras palavras, as reflexões de Fanon nos permitem pensar como, entre aqueles que habitam esta zona, o desprivilégio racial é vivido de acordo com as dimensões de classe, gênero, sexualidade, cor da pele, nacionalidade etc. Da mesma forma, suas contribuições nos permitem pensar na zona do ser como uma zona heterogênea, em que o privilégio racial é entrecortado por diversos outros eixos de poder: classe, gênero, religiosidade, idioma, sexualidade, nacionalidade etc. (Grosfoguel, 2012)" (BERNARDINO-COSTA, 2016, p. 509).
} 
formas de subjetivação, ou seja, maneiras de se produzir autoconhecimento, viver, interpretar a vida engendrando assim formas condicionadas na apropriação e uso do espaço. A busca pela hegemonia (que rapidamente se torne supremacia cultural) revela que o exercício do poder além de expressar circularidade ${ }^{8}$ (estar em todo lugar) e impor constrangimentos possui também um caráter produtivo (produz novos discursos, novas classes de conhecimento, novas práticas) (HALL, 2010). Em outras palavras, há um contexto normativo marcado por princípios racistas de hierarquias valorativas tácitas que perpassam as práticas cotidianas e alicerçam as representações (MENDONÇA, 2007).

O racismo brasileiro também traz silêncios. Há distintas formas de silêncios (ORLANDI, 1997) que podemos pensar para analisar o racismo: 1- das políticas de silenciamento deliberado das violências que o racismo provocou e ainda provoca. Vê-se o esquecimento consciente como projeto racial que atinge a preservação dos lugares de memória (NORA, 1993) dos patrimônios negros e da diáspora (OLIVEIRA, 2019); 2silêncio racialmente seletivo para blindar privilégios. Gesta-se aí um racismo aversivo.

Racismo aversivo é um dos termos utilizados para caracterizar este racismo contemporâneo (Dovidio; Gaertner, 2004). Um racista aversivo não exibe preconceito racial explícito. Isto é, este indivíduo tem uma simpatia genuína pelas vítimas de injustiças e está comprometido com os princípios da igualdade racial. Ao mesmo tempo, ele/ela tem inclinações implícitas que favorecem os brancos em detrimento dos negros (Nosek et al., 2007). (WILLIAMS \& PRIEST, 2015, p. 131).

Para Mbembe (2014) a palavra 'Negro' remete, a uma fantasmagoria que é produto de uma técnica e uma máquina social do capitalismo. Na modernidade o Negro foi "[...] o único de todos os seres humanos cuja carne foi transformada em coisa, e o espírito, em mercadoria - cripta viva do capitalismo" (Idem, p. 19). O negro, na perspectiva eurocêntrica, expressa uma realidade de uma vida vazia de sentido, aprisionado na rede de dominação da raça que está em constante movimento para o nada. Para este autor, o nome negro foi inventado para significar exclusão, embrutecimento e degradação expressando um poço de alucinações. Para Mbembe (2014) a origem do termo negro é carregada de três dimensões que estão mescladas e são indissociadas: 1 - o negro como marca de um símbolo para morte (um jazigo); 2- o negro como uma marca histórica

\footnotetext{
8 "La circularidad del poder es especialmente importante en el contexto de la representación" (HALL, 2010, p. 433)
} 
símbolo de um continente destituído de humanidade (negro e África são termo coproduzidos), em suas formas disformes, da não estética, o antípoda do branco europeu; 3- a origem do termo negro está relacionado a um estado pré-civilizatório, animal e instintivo, sem razão. A invenção do negro na modernidade será, concomitantemente, um projeto racial de espaço que remonta a África.

\title{
COMO FOI INVENTADO ESSE PROBLEMA RACIAL?
}

O racismo brasileiro inventou o negro como um problema espacial. Isso começa já no momento do sequestro na África. Ou seja, no momento da destituição identitária dos Cabindas do Congo, os Benguelas de Angola, os Macuas e Anjicos de Moçambique, os Minas da costa da Guiné, os Gegês do Daomé, os Hauças do Noroeste da Nigéria, os Yorubas ou Nagôs do reino de Oyo e Ketu para invenção de uma identidade homogeneizadora colonial de negro. James (2010, p. 22) afirma que no contexto do sequestro na África, grupos escravizados no interior eram "amarrados juntos uns dos outros em colunas, suportando pesadas pedras de 20 ou 25 quilos para evitar tentativas de fuga; então marcha uma longa jornada até o mar". Ou seja, o controle da mobilidade, a interdição espacial e a contenção territorial se constituíram como marcas do processo de desreterritorialização (HAESBAERT, 2014). Não há contenção sem contornamentos e poder sem resistência (HAESBAERT, 2014; FOUCAULT, 1979) ${ }^{9}$.

\begin{abstract}
Mesmo sob a ameaça do chicote, o escrav[izad]o negociava espaços de autonomia com os senhores ou fazia corpo mole no trabalho, quebrava ferramentas, incendiava plantações, agredia senhores e feitores, rebelava-se individual e coletivamente. Houve no entanto um tipo de resistência que poderíamos caracterizar como a mais típica da escravidão - e de outras formas de trabalho forçado. Trata-se da fuga e formação de grupos escrav[izad]os fugidos [e a criação de quilombos] (GOMES \& REIS, 1996, p. 09).
\end{abstract}

James (Idem) afirma outro dispositivo espacial que inventou o negro como o problema, foram a redução e o confinamento ainda nos portos na África.

Nos portos de escrav[izad]os, eles permaneciam amontoados em um cercado para a inspeção dos compradores. Dia e noite, milhares de seres humanos eram apinhados em minúsculas galerias nos 'depósitos de putrefação', onde nenhum

\footnotetext{
${ }^{9}$ Não há poder sem resistência, diria Foucault (1979). Daí o exercício do poder torna-se paranoico a qualquer tipo de distensão.
} 
europeu conseguiria permanecer por mais de quinze minutos sem desmaiar. Os africanos desmaiavam e se recuperavam ou, então, desmaiavam e morriam; mortalidade naqueles 'depósitos' era maior do que vinte por cento (JAMES, 2010, p. 22).

O confinamento seleciona os mais fortes. Nos navios negreiros, a continuidade do confinamento espacial, eram espremidos nos porões insalubres. Um regime de calculada brutalidade e terrorismo (JAMES, 2010) se constituíam. O foco era produzir corpos amedrontados e dóceis (Idem) garantindo a sensação racial de segurança (OLIVEIRA, 2019) dos proprietários e a chegada das mercadorias, os escravizados. Estima-se que pelo oceano, conhecido como a grande Kalunga (o grande cemitério) morriam entre 10 e $20 \%$ de escravizados em revoltas, naufrágios, doenças, suicídio e assassinatos. Impactava distintamente homens e mulheres. James (2010, p. 28) afirma que "após aquela terrível viagem pelo oceano, era comum que as mulheres ficassem estéreis durante dois anos". O navio negreiro simbolizava a reafirmação do negro (esse ser que estava sendo inventado pelo colonizador) como um problema espacial que necessitava de controle e disciplina. Corpos nus acorrentados num espaço imundo durante semanas, às vezes meses, para serem vendido em outro continente. Lembremos que os navios negreiros eram também conhecidos como tumbeiros, isto é, espaço de morte. O negro como problema espacial para o branco é marcado pela ideia de segurança que nasce carregada de subsídios raciais (MBEMBE, 2014). Segurança significa aí a mensuração do risco para os brancos nas suas trajetórias geográficas.

A ideia de risco parece ter se estabelecido no século XVI e XVII, e foi originalmente cunhada por exploradores ocidentais ao partirem para suas viagens pelo mundo. A palavra 'risk' parece ter se introduzido no inglês através do espanhol ou do português, línguas em que era usada para designar a navegação rumo a águas não cartografadas. Em outras palavras, originalmente ela possui uma orientação espacial. Mais tarde, passou a ser transferida para o tempo, tal como usada em transações bancárias e de investimento, para designar o cálculo das consequências prováveis de decisões de investimento para os que emprestavam e os que contraíam empréstimos. Mais tarde passou a designar uma ampla esfera de outras situações de incerteza (GIDDENS, 2007, p. 32).

A ideia de risco nasce do lócus de enunciação branco na busca de se orientar para definir um projeto colonial. A ausência de mapa, de disciplina dos corpos escravizados e o biopoder (quem pode morrer e quem deve viver) provocava mais risco. 
Controle, disciplina, adestramento e domesticação eram os focos da produção de servos voluntários (LA BOÉTIE, 1999 [1549]), isto é, seres obedientes educados a quererem ser um opressor (FREIRE, 2001) e garantir a segurança do colonizador. Os servos voluntários são cumpridores de ordens e leais a dominação. São oprimidos educados para delatar revoltas iminentes. Os servos voluntários não são regidos pela lógica do medo e/ou da covardia. São educados para serem servos (Idem). Liberdade é ser servo de um senhor. São oprimidos que estabelecem cumplicidades com o opressor para viverem uma ilusão de pertencimento a zona do-ser. O cristianismo tanto no contexto colonial quanto pós-colonial foi e continua sendo um dos principais agentes na produção da servidão voluntária. O servo voluntário não está sendo enganado. É o oprimido educado para oprimir outros oprimidos e adorar o opressor. Escravidão e servidão voluntária são inerentes ao projeto de dominação racial brasileira.

Os porões dos navios negreiros além de um espaço de confinamento e controle dos corpos era também um espaço de concentração de raiva, por isso o medo branco da onda negra (AZEVEDO, 1987). A "raiva é uma resposta às atitudes racistas e às ações e presunção que surgem dessas atitudes" (LORDE, 2019). Nesse espaço que nasce a ideia do medo branco da concentração espacial de negros, isto é, uma sensação racial de insegurança. Mas essa raiva não era fruto de ressentimentos, mas de homens e mulheres que se recompunham contra a violência que sofriam (FANON, 1968). A raiva é a não aceitação da condição imposta pelos colonizadores. A raiva ameaça o modo de vida (LORDE, 2019) da branquitude, pois ela "é repleta de informação e energia" (Idem, p. 160). A raiva é sempre uma luta de um coletivo enfrentando o ódio. A raiva é aí a busca de compreensão de sentido por que está sendo agredido, menosprezado, invisiblizado e/ou silenciado.

É o ódio que espreita nessas ruas, que deseja destruir a todas que trabalharmos verdadeiramente em prol da mudança, em vez de apenas cedermos à retórica acadêmica.

Esse ódio e a nossa raiva são muito diferentes. O ódio é a fúria daqueles que não compartilham os nossos objetivos, e sua finalidade é a morte a destruição. A raiva é um sofrimento causado pelas distorções entre semelhantes, e o sua finalidade é a mudança (LORDE, 2019, p. 161). 
A raiva "rejeita a atualidade e o devir em nome de um passado místico" (FANON, 2008, p. 31). O ódio é a expressão de negação de uma existência. Ele cria respostas geográficas: contenções territoriais e confinamentos espaciais (HAESBAERT, 2014).

A proximidade de tantos corpos humanos nus com a pele machucada e supurada, o ar fétido, a desinteira generalizada e a acumulação de imundícies tornavam esses buracos um verdadeiro inferno. [...] Nenhum lugar na Terra, observou um escritor da época, concentrou tanta miséria quanto o porão do navio negreiro. [...] Morriam não apenas por causa do tratamento, mas também por mágoa, de raiva e de desespero. Faziam longas greves de fome; desatavam as suas cadeias e se atiravam sobre a tripulação numa tentativa inútil de revolta. $\mathrm{O}$ que poderiam fazer esses homens de remotas tribos do interior, no mar aberto, dentro de um barco tão complexo? Para avivar-lhes os ânimos, tornou-se costume leva-los ao tombadilho uma vez por dia e obriga-los a dançar ${ }^{10}$. Alguns aproveitavam a oportunidade para pular ao mar gritando em triunfo enquanto se afastavam do navio e desapareciam sob a superfície (JAMES, 2010, p. 23).

O navio negreiro forjou uma complexa diversidade de racismos que foi estruturando espacialmente a sociedade brasileira: 1- racismo ambiental, ao instituir uma geografia dos rejeitos sociais como lugares de negros e dos proveitos sociais como lugares dos brancos (PORTO-GONÇALVES, 2006); 2- um racismo recreativo ${ }^{11}$ (MOREIRA, 2019) que define o negro como um ser grotesco, para o divertimento do branco. Retirase a violência do horizonte ético no trato dos negros; 3-a gestão bio-necropolítica do espaço ao definir uma política administrada de morte para manter a disciplina, o controle e a ordem espacial (OLIVEIRA, 2015); 4- o cinismo que definia que brutalidade não se aplica aos negros, já que são não-seres, ou seja, não-humanos ou humanos de menos valor (Idem). Afirma-se aí a ideia de um racismo cordial ${ }^{12}$. Logo, "a verdade de que o racismo

\footnotetext{
${ }^{10}$ Ver o poema "O navio negreiro", de CASTRO ALVES: "Era um sonho dantesco ... O tombadilho $\backslash$ Que das luzernas avermelha o brilho, $\backslash$ Em sangue a se banhar. $\backslash$ Tinir de ferros ... estalar do açoite ... \Legiões de homens negros como a noite, $\backslash$ Horrendos a dançar ... (...) Presa nos elos de uma só cadeia, $\backslash$ A multidão faminta cambaleia, \E chora e dança ali! (...) No entanto o capitão (...) $\backslash$ Diz do fumo entre os densos nevoeiros: ‘'Vibrai rijo o chicote, marinheiros! \Fazei-os mais dançar!...”. (N. do T.)

${ }^{11}$ Moreira (2019) afirma que ele se constitui com o uso do humor contra negros que ideologicamente se afirma como benigno, mas que: 1- propaga uma hostilidade racial; 2- bestializa os negros; 3 - busca produzir um ser programado para servir o branco; 4- uma forma de degradação do negro buscando impedir o acesso a comunidade política.

${ }^{12}$ A crença de que eles estavam fazendo "um bem para os escravizados" revela-se no contexto de escravização na África e no nome de inúmeros navios negreiros criando um tipo de racismo conhecido como cordial.
}

$\mathrm{Na}$ África no período colonial essa crença é expressa quando os escravagistas obrigavam os escravizados a fazerem "o ritual [de dar voltas] em torno dessa árvore do esquecimento [o baobá] para deixarem suas 
extorque por onde passa, cobra vidas a rodo, trucida potencias e sonhos sem remorso" (FLAUSINA, 2017, p.18)

Esse violento processo de desreterritorialização reduziu a diversidade de povos a condição de objeto. A ideia de negro nasceu como o não-ser e a expressão do nada (FANON, 2008; SARTRE, 2007). No entanto, os povos escravizados não só trouxeram seus corpos para o trabalho, mas também seus princípios epistemológicos e ontológicos cosmogônicos, as metafísicas de divindades e religiosidades, saberes ancestrais étnicobotânicos, de mineração, agricultura em ambiente tropical/equatorial, técnicas de metalurgia que se territorializará na diáspora.

[...] com eles, sua cultura, seus saberes e conhecimentos técnicos também fizeram deles uma força de caráter civilizatório. Os africanos ensinaram aos habitantes do território brasileiro e das Américas escravistas muitas coisas fundamentais para a sobrevivência e o crescimento do chamado "Novo Mundo".[...] Foram artífices, construtores, cirurgiões-barbeiros, cozinheiras. Foram agricultores que trouxeram plantas novas, que serviram e servem como alimento e remédio, e também introduziram diferentes técnicas de cultivo. Entre esses escrav[izad]os havia artistas e músicos com novos instrumentos, ritmos e movimentos que encheram nossa terra de cores e sons - que hoje são tão nossos, tão brasileiros. E suas línguas modificaram o português, fizeram dele a língua nacional, levando-o pelo território, introduzindo palavras e tonalidades [o pretuguês como lembra Lélia Gonzalez (1988)]. E também trouxeram novas maneiras de se comportar nas relações familiares, de se relacionar com o sagrado, novos modos de celebrar e de se ligar aos antepassados, ou seja, posturas diante da vida e da morte. (LIMA, 2006, p. 45)

Apesar da exploração e espoliação, os escravizados com seu impulso de vida e o brilho de seu espírito. Em outro trabalho afirmamos que os escravizados carregavam

Várias Áfricas aqui se inscreveram e os corpos dos escravizados eram uma espécie de arquivo de paisagens perdidas e mundos desfeitos e refeitos, eram o alvo das discriminações e usados como arma para defesa de seu único território (TAVARES, 1984).

vidas, histórias e culturas para trás e então serem rebatizados com nomes cristãos" (ALE SANTOS, 2019, p. 11)

Já com relação o nome dos navios negreiros o racismo cordial poderia ser percebido nos seguintes nomes: Amável Donzela (1788 a 1806), Boa Intenção (1798 a 1802), Brinquedo dos Meninos (1800 a 1826), Caridade (Quatro diferentes embarcações usaram esse nome - 1799 a 1836), Feliz Destino (1818 a 1821), Feliz Dias a Pobrezinhos (1812), Graciosa Vingativa (1840 a 1845), Regeneradora (Três embarcações usaram esse nome - 1823 a 1825) poderíamos perceber esse dito racismo cordial que dissimula violências (MANENTI, 2015). 
A luta pelo reconhecimento e defesa dos patrimônios (materiais e imateriais) da diáspora africana expressam histórias e memórias invisibilizadas e apagadas pelo imaginário colonial eurocêntrico que, infelizmente, ainda se perpetua em nossa sociedade. Pensar em africanidades no Brasil é pensar as Áfricas que nos formaram enquanto sociedade, nação e território. As africanidades revelam marcas das distintas "matrizes africanas" na memória da formação brasileira que aqui se territorializaram e se reinventaram. Logo, as africanidades não são dadas, elas são (re)construções de discursos explícitos e ocultos de uma multiplicidade de povos que aqui se estabeleceram, de forma tensa e contraditória (OLIVEIRA, 2016).

Assim, a consciência Negra na alvorada do capitalismo irá emergir na dinâmica do movimento e da circulação (Idem), pois a diáspora ao colocar as pessoas de origem de distintas partes da África no centro deste processo forçado de desreterritorialização, impôs a essa multiplicidade de povos e nações de distintas localidades e trajetórias, uma consciência de uma experiência comum, a luta contra escravidão e a dominação racial.

James (2010) aponta distintas modalidades de poder e resistências que resultaram nas mortes de escravizados nos navios negreiros. "Ao contrário das mentiras que foram espalhadas tão insistentemente da docilidade do negro, as revoltas nos portos de embarcação e a bordo eram constantes" (Idem, p. 22). Os escravizados eram assassinados devido ao exercício biopolitico, isto é, deixar viver para serem escravizados e fazer morrer os revoltosos. Chegavam desnutridos, com feridas infecionadas, com várias doenças devido ao espaço insalubre que eram os navios negreiros. Vemos que séculos antes do darwinismo social ter difundido suas ideias, a lógica biopolítica no período colonial era os mais fortes sobrevivem. O poder soberano também vigia nos navios negreiros. James (2010, p. 23) lembra que:

Por medo da carga [isto é, medo dos escravizados], uma crueldade selvagem se desenvolvia na tripulação. Um capitão, para inspirar terror nos escrav[izad]os, matou um deles e repartiu seu coração, seu fígado e suas entranhas em trezentas partes, obrigando os outros escrav[izad]os a comê-los, ameaçando aqueles que não o fizessem com o mesmo suplício. (DE VAISSIÈRE, Saint-Domingue, p. 162.)

Tomadas de embarcações feitas por quilombolas em navios aportados aparecem timidamente na história eurocentrada ${ }^{13}$. Ademais, os escravizados também morriam por

\footnotetext{
${ }^{13}$ Reza a lenda que Zacimba, princesa da nação Cambinda, que foi escravizada, sequestrada e levada para o porto de São Matheus, no Espírito Santo em 1690, após envenenar seu 'dono' liderou a tomada de
} 
mágoa, enlouquecimento, greves de fome, tristeza (o banzo), desespero, revoltas nos navios negreiros e raiva. Sob a raiva Lorde (2019) nos diz: "é uma reação apropriada para atitudes racistas, como é a fúria quando as ações que surgem daquelas atitudes não mudam" Eram potencias de vidas que estavam sendo apagadas pelo projeto escravocrata.

Um complexo espacial foi inventado nas cidades portuárias para afirmação desta distinção corpórea de direitos (BARBOSA \& BARBOSA, 2017). Essa distinção corpórea de direitos (Idem) era um dispositivo bio-necropolítico. Esse complexo espacial era, em geral, formado pelos cais (local de chegada), valongo (local de venda), lazareto (local de restituição das força dos escravizados doentes), cemitério de pretos novos (local de despejo dos corpos não sobreviventes), senzala (local de confinamento para posterior dinâmica do trabalho). Neste complexo espacial era consolidado, em terra brasilis, a distinção corpórea de direitos (Ibidem) que expressa a desumanização de expressividade de vidas corporificadas para o trabalho extenuante. Foram geo-grafias de produção de não-existência ${ }^{14}$.

Um complexo contra-espacial de forma imanente era gestado formado por zungus, terreiros, rodas culturais, quilombos, a santuarização de territórios (a mata, o rio, o mar, a cachoeira, o lago, a lagoa, a encruzilhada, pedreira). Esse complexo contra-espacial é marcado por biopotências. Suas formas de ação se expressam da curta a longa duração, do discurso explícito aos discursos ocultos, elas podem está inscritos na paisagem natural, isto é, da natureza socialmente construída que emerge nas ervas, plantas, pedreiras, matas, rios, mar, cachoeira, mangue aos símbolos na arquitetura de prédios coloniais de culturas africanas, nas técnicas de construções e sistemas de engenharias de túneis e galerias de povos mineradores da diáspora na exploração colonial. Rastros de resistências e rexistência nas cidades tem sido historicamente invisibilizadas e apagadas.

\section{RASTROS HISTÓRICOS DO GENOCÍDIO NEGRO}

Mbembe (2014) defende que a modernidade foi um projeto de conhecimento e de governança. Conhecer para poder produzir com mais eficácia uma vida contingenciada.

embarcações de escravizados aportados. "O sucesso dos ataques afastou muitos navios negreiros da região" (ALE SANTOS, 2019, p. 58).

${ }^{14}$ Irmandades negras foram criadas no enfrentamento a distinção corpórea de direitos (BARBOSA \& BARBOSA, 2017) e o direito de ser enterrado dignamente. 
Para Mbembe (Idem) a modernidade foi formada por dois delírios. O primeiro delírio da modernidade "[...] o Negro ser aquele (ou ainda aquele) que vemos quando nada se vê [ou seja, um estatuto de não existência, ou como diria Fanon (2008), a zona do não-ser], que nada compreendemos e, sobretudo, quando nada queremos compreender" (MBEMBE, 2014, p. 11). Entendemos que este delírio legitima um genocídio e um epistemicídio como projeto de dominação e aniquilamento de Desejos Negros.

O segundo delírio da modernidade expressa à negação de si e para-o-outro, pois, "ninguém - nem aqueles que inventaram nem os que foram englobados neste nome desejaria ser um negro ou, na prática, ser tratado como tal” (MBEMBE, 2014, p. 11).

A solução, no contexto colonial, era é o castigo do sistema pelourinho quando não sabe seu lugar. Chamamos de sistema por se constituir num dispositivo pedagógico de humilhação e crueldade que se aplicará a todos os Negros que se revoltem. Essa programação não foi eliminada com o fim do colonialismo. Ela define a sensação racial de segurança e indivíduos espacialmente programados, isto é, um uso do espaço por critérios raciais (AZEVEDO, 2018). "Neste mundo maniqueísta, espera-se dos condenados da terra o cumprimento de determinados papéis sociais e a circulação restrita a determinados espaços sociais" (BERNARDINO-COSTA, 2016, p. 510).

No contexto colonial, o pelourinho era um dispositivo disciplinar do exercício do poder racial que afirmava a existência e a presença do soberano que garantia a ordem para escravismo colonial. O pelourinho era um local de castigo e suplicio dos Negros que se revoltavam contra a ordem instituída. Constituiu-se como um dispositivo de aplicação de justiça colonial que foi trazido pelos colonizadores da Europa da era medieval e restituído nas colônias (MALAFAIA, 1997) ${ }^{15}$. Através de uma pena pública tinha como finalidade impedir, pelo temor, a repetição e/ou imitação da realização do Desejo Negro, isto é, ser o senhor do seu destino e livre-por-si. Uma prevenção de 'males' futuros. Lembremos que liberdade com o projeto da moderno-colonialidade se constituiu como um privilégio dos homens brancos, heterossexuais e com posses. Compreendemos, portanto o pelourinho como um emblema paisagístico da autoridade moderno-colonial posto num local central da cidade para punir os Negros indisciplinados instituindo uma ordem em defesa da sociedade (FOUCAULT, 2005) branca. O pelourinho, em geral era "colocado

\footnotetext{
${ }^{15}$ A ideia de Justiça nasceu no Brasil marcada como política contra a vida dos negros. Uma gestão bionecropolítica dos territórios e das populações negras (OLIVEIRA, 2015).
} 
em lugar central e dominante da povoação, em geral em frente à Câmara, Tribunal ou Cadeia, era o lugar de aplicação de penas menores e sempre de exposição ao conhecimento, ridículo e vergonha por parte dos vizinhos. Era esta a regra" (MALAFAIA, 1997, p. 41/42). Não era o local para se aplicar a pena de morte, mas dispositivos para advertir o Negro da culpa do seu próprio castigo e/ou morte acidental no castigo. $\mathrm{O}$ foco era disciplinar e produzir comportamentos espaciais submissos ponhase no seu devido lugar elou permaneça no seu devido lugar (OLIVEIRA, 2011). Sair do seu lugar imposto significa autorizar tanto o exercício da gestão racialmente bionecropolítica dos territórios e populações quanto "o olhar imperial tentará restituí-lo à sua posição 'natural', à zona do não-ser, por meio da violência simbólica ou física" (BERNARDINO-COSTA, 2016, p. 510). Entendemos que o pelourinho além de afirmar um poder racial disciplinar, tinha também elementos biopolíticos, pois fazia morrer pelas feridas abertas com as chibatas (assim o senhor nunca poderia ser considerado assassino, pois se definia que o Negro não teve cuidado consigo) ou deixar viver se obedecer às ordens raciais no uso e apropriação dos espaços e escalas (Idem). Nesta ótica, o castigo era visto no passado colonial como um justo merecimento. Sua actualidade ${ }^{16}$ persiste e insiste como um problema espacial no neoliberalismo.

A política de gestão da vida tem a marca no pelourinho. Já gestão da morte (física e simbólica) dos Negros como sujeito político que estabelecem um contra-espaço, como os quilombos, deve morrer tanto em termos materiais quanto simbólicos (totalmente esquecido e que não vire exemplo). Lembremos que no contexto da Revolta dos Malês na Bahia, muitos revoltosos não foram mortos, mas deportados (morte simbólica) para se retirar do campo visual e não se tornar exemplo, isto é, deportar os que poderiam ensinar a transgredir (hooks, 2013). Os mundos afros recriam, com os processos de reterritorialização, novas consciências de si, para si e para os outros frente a distinção corpórea de direitos (BARBOSA \& BARBOSA, 2017) característico da escravidão racial. Essas consciências de si, para si e para os outros expressam aquilo que Fanon (2008, p. 184) chama de "alteridade de ruptura, de luta, de combate". Essas consciências não são dadas. Elas são historicamente construídas e espacialmente georreferenciadas por ações políticas em determinados contextos sócio-espaciais e políticos. Elas criam, recriam

16 "actual, es decir, algo de otro tiempo que actúa aquí y ahora, a partir de nuevas circunstancias" (GONÇALVES, 2001, p.125). 
e inventam tradições.

Por "tradição inventada" entende-se um conjunto de práticas, normalmente reguladas por regras tácita ou abertamente aceitas; tais práticas, de natureza ritual ou simbólica, visam inculcar certos valores e normas de comportamento através da repetição, o que implica, automaticamente; uma continuidade em relação ao passado. Aliás, sempre que possível, tenta-se estabelecer continuidade com um passado histórico apropriado. (HOBSBAWN \& RANGER, 1997, p. 10)

As cidades brasileiras nasceram para exterminar os Negros enquanto sujeito de direitos (OLIVEIRA, 2014) e suas tradições (re)inventadas (HOBSBAWN \& RANGER, 1997) na diáspora. No contexto colonial, o pelourinho era parte de um dos dispositivos que definia uma estrutura ordenadora institucional ativada, em determinados momentos e contextos espaciais públicos, para afirmação de uma ordem espacial racialmente hierárquica. Os elementos simbólicos que alimentavam esse dispositivo punitivo não foram abolidos com o fim do colonialismo. Este dispositivo punitivo é alimentado por estereótipos como práticas significantes (HALL, 2010). Eles não só atingem aos corpos Negros, mas também suas tradições diásporicas (re)inventadas. Eles buscam forçar pessoas e/ou grupos afro-religiosos a estarem fora do seu lugar, e/ou do caminho da branquitude. Essas estruturas têm sido restituídas nas cidades actuais no contexto neoliberal tanto na morte de jovens negros quanto na perseguição e destruição de tradições Negras diaspóricas de matrizes religiosas afro. Contudo, formas plurais políticas de luta e agenciamento no combate ao racismo gestando contra-espaços perenes e/ou eventuais promovendo furos na realidade.

\section{GENOCÍDIO NEGRO NO CONTEXTO NEOLIBERAL}

A luta antirracista actual envolve a forma de como tem se problematizado a questão racial brasileira. Ela tem produzido disputas de narrativas dos sentidos das existências negras tanto pretérita quanto presente. Logo,

Resistir é desviar(-se) para não ter que se chocar sempre contra um poder, uma força maior. Resistir é dobrar(-se), mas nem por isso se deixar subjugar totalmente. Resistir é curvar(-se) de tal formar que as linhas de força não se imponham, ainda que sejam mínimas curvaturas. Resistir é deslocar(-se) de tal modo que se possa fugir, criar linhas de fuga (DELEUZE e GUATTARI, 1995), ocupar outros lugares, reposicionar-se. Toda forma de resistência implica em 
alguma forma de deslocamento, desvio, curvatura e dobra, por mais sutis ou insignificantes que pareçam nas relações de poder. Nem sempre a resistência necessita fazer alarde, barulho, ganhar relevo, tornar-se explícita, criar grandes agitações e abalos sísmicos. As resistências cotidianas são silenciosas e tenazes (SCOTT, 2002; 2004; 2011). De várias formas podemos encontrar a resistência, no mundo atual. Várias formas de resistência são praticadas por grupos sociais subalternizados. Muitas vezes, estas envolvem estratégias e táticas (CERTEAU, 2014) que são territoriais. [...] Em contextos pós-coloniais, de sociedades que foram colonizadas, não apenas em territórios de ex-colônias, mas também nos territórios das antigas metrópoles, resistir apresenta-se como descolonizar. A resistência no mundo moderno-colonial, cuja matriz de poder é a colonialidade (QUIJANO, 2010; MIGNOLO, 2010), desloca, dobra, curva e desvia-se na direção de um giro descolonial (CASTRO-GÓMEZ e GROSFOGUEL, 2007; MIGNOLO, 2010; GROSFOGUEL e MIGNOLO, 2008; MALDONATOTORRES, 2008) político, epistêmico, histórico, geográfico etc. As práticas cotidianas de resistência de grupos subalternizados, historicamente, vêm alimentando, desde a constituição do sistema-mundo moderno-colonial, imaginários descoloniais, práticas descoloniais e "atitudes descoloniais" (MALDONADO-TORRES, 2006), formando o arquivo, o leque, o repertório, a arena, agenda e agência da "opção descolonial" (MIGNOLO, 2008). A resistência subalterna aponta para a construção de novos "horizontes de sentidos" descoloniais (QUIJANO, 2013) ; (PEREIRA, 2017, p. 18/19-20).

No contexto urbano neoliberal de países de formação colonial como o Brasil resistir envolve compreender tanto o exercício de poder quanto as lutas da longa duração. A busca por desmobilizar as resistências e/ou funcionalizá-las para a reprodução dos interesses do capital tem criado sofisticada formas de luta.

Se considerarmos as modalidades "veladas" de resistência, em suas formas cotidianas (SCOTT, 2004; 2011), resistência é mais que uma simples reação ao poder: é r-existência: "o que se tem é R-Existência posto que não se reage, simplesmente à ação alheia, mas, sim, que algo pré-existe e é a partir dessa existência que se R-Existe. Existo, logo resisto. R-Existo" (PORTOGONÇALVES, 2006, p. 47). Esta r-existência é luta por "uma determinada forma de existência, um determinado modo de vida e de produção, por modos diferenciados de sentir, agir e pensar" (PORTO-GONÇALVES, 2010, p. 130, grifo nosso) - ou o que Scott $(2004 ; 2011)$ tem chamado de "resistência cotidiana", que se apresenta de várias formas, não necessariamente por meio de lutas, confrontos diretos, rebeliões ou revoltas (PEREIRA, 2017, p. 28).

Na cidade neoliberal resistir ao genocídio tem se constituído numa dura tarefa que tido o protagonismo de mães que tem seus filhos assassinado pelo Estado. A sensação racial de in-segurança torna-se a tônica no contexto neoliberal. A cidade, no contexto neoliberal, não é criada para se viver, mas sim para se exibir (BARBOSA, 2002) segurança. O negro como problema espacial permanece e se amplia. As relações cínicas 
das instituições brasileiras voltadas para exportar a imagem do Brasil, em particular do Rio de Janeiro, invisibilizam o genocídio e visibilizam um discurso ideológico da democracia racial.

O neoliberalismo ao reduzir tudo à mercadoria intensifica a "[...] produção da indiferença, a codificação paranoica da vida social em normas, categorias e números, assim como por diversas operações de abstracção que pretendem racionalizar o mudo a partir de lógicas empresariais ${ }^{17 "}$ (MBEMBE, 2014, p. 13) Assim, a política criminal neoliberal actualiza a barbárie genocida contra o povo negro (FLAUZINA, 2006), pois naturaliza as relações sociais moderno-colonialmente instituídas. $\mathrm{O}$ neoliberalismo se constituiu como um "excepcional extrato purificador" que define que tipo de sociedade/espaço a ser racialmente preservada (LANDER, 2000). Recomendações raciais na gestão do território pelas autoridades tem se constituído (MBEMBE, 2014).

A primeira recomendação é a recusa de ver o extermínio de jovens negros (mesmo apesar dos dados) e a segregação racial do espaço. A segregação aliada a precarização territorial (a exemplo de falta de saneamento básico e de serviços médicos adequados) é uma estratégia biopolítica de expor a vida a elementos provocadores da morte (AGAMBEN, 2004). Porém, o necropoder age também mobilizando a sensação racial de in-segurança e o ódio sobre os espaços e contextos de concentração espacial de negros. O foco do Estado é fazer operações ${ }^{18}$.

Uma segunda recomendação racial que neoliberalismo difunde na gestão do território é a prática de limpeza e travestimento das mazelas sociais (especialmente, a população em situação de rua e as chamadas 'cracolândias') nos espaços vitrines e nos trajetos do turismo internacional. A biopolítica se revela na absorção de um poder medical para higienizar a paisagem desses espaços e trajetos.

Já a terceira recomendação racial do neoliberalismo na gestão territorial das cidades é a frivolidade e o exotismo, ou seja, destituir o valor político as africanidades (OLIVEIRA, 2016) construídas por heranças do passado quanto de tradições (re)inventadas (HOBSBAWN \& RANGER, 1984) transmutadas de mundos africanos na

\footnotetext{
${ }^{17}$ Ver Béatrice Hibou, La Spectre du capital, Diaphanes, Paris, 2013, p. 152.

${ }^{18}$ Termo utilizado para referirem-se as ações policiais no Rio de Janeiro, em geral em áreas pobres e/ou com grande concentração de pessoas negras em que o necropoder é legitimo. O terror e a barbárie tornamse banais nestas operações para os aparatos públicos de in-segurança.
} 
diáspora. Ademais, vemos a transformação em turismo despolitizado recriando novos zoo humanos à cidade do Rio de Janeiro (vide os safaris para as favelas da zona sul patrocinado pela secretaria de turismo para os transatlânticos).

\section{CONSIDERAÇÕES FINAIS}

Neste contexto, o Estado de Exceção tornou-se o paradigma dominante apresentando como forma legal, aquilo que não pode ter forma legal (AGAMBEM, 2004). "En la economia del biopoder, la función del racismo consiste en regular la distribución de la muerte y en hacer posibles las funciones mortíferas del Estado. Es, según afirma, 'la condición de aceptabilidad de la matanza' ${ }^{19}$ (MBEMBE, 2006, p. 23) como problema espacial que ameaça aos brancos. A necropolítica torna-se a política de Estado nos espaços de maioria pobre e negra, pois negros nem quando morre aos milhões gera comoção social ou tem a dignidade de ser corpos respeitados (vide as alterações de cena de crimes para incriminar as vítimas negras).

As marcas coloniais persistem, são recriadas e novos padrões de poder nascem nas cidades no contexto neoliberal. Compreender esses dispositivos podem ajudar a compreender uma das chaves do negro ser visto como um problema espacial, criar novos instrumentos de luta e romper coma lógica eurocêntrica na leitura de mundo que tem justificado o genocídio negro.

\section{REFERÊNCIAS BIBLIOGRÁFICAS}

ALE SANTOS. Rastros de Resistência: histórias de luta e liberdade do povo negro. São Paulo: Panda Books, 2019.

AGAMBEM, G. Estado de exceção: homo sacer. São Paulo: Boitempo, 2004.

ALMEIDA, S. L. O que é racismo estrutural? Belo Horizonte (MG): Letramento, 2018.

AZEVEDO, C. M. M. Onda negra, medo branco: o negro no imaginário das elites no século XIX. Rio de Janeiro: Paz e Terra, 1987.

AZEVEDO, S. S. O uso do espaço marcado por critérios raciais: Uma análise a partir dos rolezinhos. São Gonçalo: FFP:UERJ - Trabalho de Final de Curso, 2018.

${ }^{19}$ Ibid. , p. 10

Revista da ABPN • v. 12, n. Ed. Especial - Caderno Temático: “Geografias Negras” • abril de 2020, p. 312-335 
BARBOSA, J. L. O ordenamento territorial urbano na era da acumulação globalizada. In: POSGEO/UFF. Território, territórios: ensaios sobre o ordenamento territorial. Niterói: UFF, 2002. p. $125-146$.

\& BARBOSA, A. T. A. Relações de gênero: espacialidades de poder em tempos de violência. In: BARBOSA, J. L. \& HILGERS, T. (orgs) Identidade, território e política em contextos de violências na América Latina. Rio de Janeiro: Editora Observatório de Favelas, 2017.

BENTO, M. A. S. Pactos Narcísicos no racismo: Branquitude e poder nas organizações empresariais e no poder público. São Paulo, 2002. Tese (Doutorado) Instituto de Psicologia da Universidade de São Paulo.

BERNARDINO-COSTA, J. A prece de Frantz Fanon: Oh, meu corpo, faça sempre de mim um homem que questiona! Civitas, Porto Alegre, v. 16, n. 3, p. 504-521, jul.-set. 2016.

EVARISTO, C. Becos da Memória. Florianópolis: Ed. Mulheres, 2013.

FANON, F. Pele negra, máscaras brancas. Salvador: EDUFBA, 2008. . Os Condenados da terra. Rio de Janeiro: Civilização Brasileira, 1968.

FLAUZINA, A. L. P. Apresentação. In: ALEXANDER, Michelle. A nova segregação: racismo e encarceramento em massa. São Paulo: Boitempo, 2017.

. Corpo negro caído no chão: o sistema penal e o projeto genocida do estado

brasileiro. Dissertação (Mestrado) - Universidade de Brasília, Brasília, 2006.

FOUCAULT, M. Microfísica do Poder. Rio de Janeiro: Graal, 1979.

Em defesa da sociedade. São Paulo: Martins Torres, 2005.

FREIRE, P. Pedagogia da autonomia: saberes necessários à prática educativa. Rio de Janeiro: Paz e Terra, 2001.

FREUD, S.O mal-estar na civilização, novas conferências introdutórias à psicanalise e outros textos (1930-1936) /São Paulo: Companhia das Letras, 2010.

GIDDENS, A. Mundo em descontrole. Rio de Janeiro: Editora Record, 2007. $6^{\text {a }}$ edição.

GOMES, F. S. \& REIS, J. J. Introdução: Uma história da liberdade. In: Liberdade por um fio: história dos quilombos no Brasil. São Paulo: Companhia das Letras, 1996.

GONÇALVES, C. W. P. Geo-grafias. Movimientos Sociales, Nuevas Territorialdides y sustentabilidade. Mexico: Siglo Veintiuno, 2001.

GUERREIRO RAMOS, A. Introdução crítica à sociologia brasileira. Rio de Janeiro: Andes, 1957.

HAESBAERT, R. Viver no limite. Rio de Janeiro: Bertrand Brasil, 2014.

HALL, S. Sin garantias: Trayectorias y problemáticas en estúdios culturales. Popayán: Evión editores, 2010.

HIRSCHMAN, A. O. A Retórica da Intransigência: perversidade, futilidade, ameaça. São Paulo: Companhia das Letras, 1992.

Revista da ABPN • v. 12, n. Ed. Especial - Caderno Temático: “Geografias Negras” • abril de 2020, p. 312-335 
HOBSBAWN, E. \& RANGER, T. A invenção das tradições. Rio de Janeiro: Paz e Terra, 1997 hook, b. Ensinando a transgredir: a educação como prática libertária. São Paulo: Martins Fontes, 2013.

JAMES, C. L. R. Os Jacobinos Negros. São Paulo: Boitempo, 2010.

LANDER, E. Ciências Sociais: saberes coloniais e eurocêntricos. In: LANDER, E. (org.) A Colonialidade do saber: eurocentrismo e ciências sociais. Perspectivas latino-americanas. Buenos Aires: CLASCO, 2000.

LA BOÉTIE, E. Discurso da servidão voluntária. São Paulo: Brasiliense, 1999 [1549].

LIMA, M. Como os tantãs na floresta: reflexões sobre o ensino de História da África e dos africanos no Brasil. In: Saberes e fazeres, v.1: modos de ver / coordenação do projeto Ana Paula Brandão. Rio de Janeiro: Fundação Roberto Marinho, 2006.

MALAFAIA, E. B. A. Pelourinhos portugueses - Tentâmen de Inventário Geral. Coleção Presença da Imagem - Imprensa Nacional - Casa da Moeda. Dezembro de 1997.

MANENTI, C. Lista com nomes de navios negreiros escancara cinismo dos comerciantes de seres humanos no Oceano Atlântico. 24/04/2015 Retirado de https://www.geledes.org.br/listanavios-negreiros-cinismo-comerciantes-seres-humanos-oceano-atlantico/.

MASSEY, D. B. Pelo espaço: uma nova política da espacialidade. Rio de Janeiro: Bertrand Brasil, 2015.

MBEMBE, A. Crítica da razão negra. Lisboa: Antígona, 2014. - Necropolítica. Sevilla: Fundación BIACS. 2006.

MOREIRA, A. Racismo recreativo. São Paulo: Pólen, 2019.

NORA, P. Entre memória e história: a problemática dos lugares. Projeto História, São Paulo, n. 10, p. 7-28, dez. 1993.

LORDE, A. Usos da raiva: mulheres respondendo ao racismo. In: Irmã outsider. Belo Horizonte: Autêntica, 2019.

OLIVEIRA, D. A. Por uma Geografa das relações raciais: o racismo na cidade do Rio de Janeiro. 2011. 274 f. Tese (Doutorado em Geografa), Instituto de Geociências, Universidade Federal Fluminense, Niterói, 2011.

. O marketing urbano e a questão racial na era dos megaempreendimentos e eventos no Rio de Janeiro. Revista Brasileira de Estudos Urbanos e Regionais. v. 16, n. 1, p. 85106, maio 2014.

. Colonialidade, biopolítica e racismo: uma análise das políticas urbanas na cidade do Rio de Janeiro. CRUZ, Valter do Carmo \& OLIVEIRA, Denilson Araújo de. (org.) Geografia e giro descolonial: experiências, ideias e horizontes de renovação do pensamento crítico . 1. ed. -- Rio de Janeiro : Letra Capital, 2017.

- Gestão racista e necropolítica do espaço urbano: apontamento teórico e político sobre o genocídio da juventude negra na cidade do Rio de Janeiro. Nova Iguaçu. Anais do Copene Sudeste, 2015.

. Africanidades. Revista Catedra Digital. Vol. 2, 2016.

Revista da ABPN • v. 12, n. Ed. Especial - Caderno Temático: “Geografias Negras” • abril de 2020, p. 312-335 
Prefácio. Um Pouco Além das Rimas: o Negro e a Cidade. Rio de Janeiro: Projeto Gráfico Samba Group, s/d. Retirado de https://afro21.files.wordpress.com/2017/02/umpouco-alc3a9m-das-rimas-o-preto-e-a-cidade.pdf em 01/08/2019. O negro: um problema espacial. Vitória. Anais do Copene Sudeste, 2019.

OLIVEIRA, L. F. O que é uma educação decolonial? In: Educação e Militância. Rio de Janeiro: Selo Novo, 2018.

ORLANDI, E. P. As Formas do Silêncio: no movimento dos sentidos. Campinas: Editora da UNICAMP, 1997.

PEREIRA, E. Resistência descolonial: Estratégias e táticas territoriais. Terra Livre São Paulo Ano 29, Vol.2, n 43 p.17-55, 2017.

PORTO-GONÇALVES, C. W. Globalização da Natureza e a Natureza da Globalização. Rio de Janeiro: Civilização Brasileira, 2006.

QUIJANO, A. Colonialidade do poder, eurocentrismo e América Latina. In: LANDER, Edgardo (Org.) A colonialidade do saber: eurocentrismo e Ciências Sociais - Perspectivas latinoamericanas. Buenos Aires: CLACSO, 2005.

SANTOS, J. R. O negro como lugar. In: MAIO, M.C., and SANTOS, R.V., orgs. Raça, ciência e sociedade [online]. Rio de Janeiro: Editora FIOCRUZ; CCBB, 1996, pp. 219-223

SARTRE, J. P. O Ser e o Nada. Petrópolis: Vozes, 2007. $15^{\text {a }}$ edição.

SCHUCMAN, L. Entre o encardido, o branco e o branquíssimo: raça, hierarquias e poder na formação da branquitude paulistana. Tese (Doutorado). Instituto de Psicologia da Universidade de São Paulo, 2012.

SIMMEL, G. A Metrópole e a Vida Mental. In: VELHO, O. G. (org) O Fenômeno Urbano. Rio de Janeiro: Jorge Zahar Ed., 1967.

WILlIAMS, D. R. \& PRIEST, N. Racismo e Saúde: um corpus crescente de evidência internacional. Sociologias, Porto Alegre, ano 17, $\mathrm{n}^{\circ}$ 40, set/dez 2015, p. 124-174.

Recebido 20/02/2020

Aceito em 30/03/2020

Revista da ABPN • v. 12, n. Ed. Especial - Caderno Temático: “Geografias Negras” • abril de 2020, p. 312-335 